\title{
36 - Avaliação radiográfica da silhueta cardíaca através do método de mensuração (VHS) em 20 cães da raça Dachshund clinicamente normais
}

Fonseca Pinto A. C. B. C.'; Iwasaki M. ${ }^{2}$; Corrêa, T. P. ${ }^{3}$; Langrafe, C. ${ }^{3}$; Sterman, F. A. ${ }^{4}$; Barbusci, L. O. D. ${ }^{5}$; Pereira G. G. ${ }^{6}$
Yoshitoshi, F. N.'; Silva, L. C. L. C.?
1- Professora Assistente do Departamento de Cirurgia da Faculdade de Medicina Veterinária e Zootecnia da Universidade de São Paulo, São Paulo-SP

2- Professor Titular do Departamento de Cirurgia da Faculdade de Medicina Veterinária e Zootecnia da Universidade de São Paulo, São Paulo-SP

3- Acadêmica da Faculdade de Medicina Veterinária e Zootecnia da Universidade de São Paulo, São Paulo-SP

4- Professor Associado do Departamento de Cirurgia da Faculdade de Medicina Veterinária e Zootecnia da Universidade de São Paulo, São Paulo-SP

5- Pós-graduanda da Faculdade de Medicina Veterinária e Zootecnia da Universidade de São Paulo, São Paulo-SP

6- Médico Veterinário contratado do Hospital Veterinário da Faculdade de Medicina Veterinária e Zootecnia da Universidade de São Paulo, São Paulo-SP

Atualmente, diferentes métodos de mensuração para avaliação radiográfica da silhueta cardíaca têm sido estudados visando diminuir o caráter subjetivo da avaliaçào empirica. $\mathrm{O}$ presente trabalho teve como objetivo aplicar o método de mensuração VHS (vertebral heart size) estudado por PINTO e IWASAKI (2002) em càes da raça Dachshund clinicamente normais, a fim de se determinar o valor médio para esta raça cada vez mais difundida em nosso meio. Para tanto, foram realizadas radiografias nas projeçōes látero-lateral direita e ventro-dorsal do tórax de 20 càes, machos e fêmeas, com idades variando de 08 meses a 07 anos. As radiografias foram avaliadas de forma subjetiva e então foram realizadas as medidas do VHS, da profundidade, e da largura do tórax. Através da avaliação empírica foram verificadas as seguintes alteraçōes: aumento global da silhueta cardíaca em 05 cães $(25 \%)$, aumento de ventrículos esquerdo e direito em 03 cães $(15 \%)$; discreto aumento de ventrículo esquerdo em 03 cães $(15 \%)$; e discreto aumento de átrio direito em 01 cão $(5 \%)$; em 08 cães $(40 \%)$ não foram observadas alterações dignas de nota. A média dos valores de VHS dos animais pertencentes a este estudo foi de 9,63 vértebras, semelhante ao limite superior proposto pelos autores de 9,5 vértebras para cães desta raça, sendo o valor mínimo de 8,7 e o valor máximo de 10,6. Em 11 animais $(55 \%)$ o VHS superou o limite superior de 9,5, sendo que destes, $08(72,7 \%)$ também obtiveram alterações radiográficas apontadas pela avaliação subjetiva. Em apenas 09 animais (45\%) observou-se VHS menor ou igual a 9,5 vértebras, e destes, $04(44,4 \%)$ apresentaram algum tipo de alteração na avaliação empirica. A classificação do tórax destes cães foi intermediária em $90 \%$ e em apenas $2(10 \%)$ obteve-se tórax tipo largo. Visto que os animais foram selecionados como clinicamente normais, pode-se dizer que a avaliaçào subjetiva tendeu a superestimar o tamanho da silhueta cardíaca e que o valor de VHS 9,5 vértebras, anteriormente descrito, foi rigoroso para ser utilizado como limite superior para os cães da raça Dachshund desta pesquisa.

\section{7 - Contribuição da Rinoscopia na avaliação de cães portadores de TVT nasal}

1- Pós-graduando do Departamento de Cirurgia da Faculdade de Medicina Veterinária e Zootecnia da Universidade de São Paulo, São Paulo-SP

2- Professor Doutor do Departamento de Cirurgia da Faculdade de Medicina Veterinária e Zootecnia da Universidade de São Paulo, São Paulo-SP

Este trabalho teve como objetivos a avaliação da cavidade nasal, através de rinoscopia, de cães portadores de afecção nasal crônica causadas por TVT, identificando a localização das lesões, correlacionando-as com os achados clínicos e radiográficos; verificar a epidemiologia 
segundo a raça, idade, peso e sexo dos animais; e definir o resultado qualitativo da biópsia. As afecções da cavidade nasal e dos seios paranasais causam, tipicamente, corrimento nasal, espirros, estertores com sons roucos ou ruidos, deformidade facial, sinais sistêmicos de enfermidade com letargia, inapetência e perda de peso, ou, em momentos raros, sinais ligados ao sistema nervoso central. As rinites podem ter etiologia primária ou secundária. Para o diagnóstico das doenças nasais deve-se incluir o exame radiográfico e o endoscópico. O tumor venéreo transmissivel (TVT) ocorre somente no cão e é uma neoplasia que acomete geralmente a genitália externa de ambos os sexos, apresentando freqüentemente regressão espontânea, todavia, metástases tem sido descritas. Esta neoplasia é distribuída amplamente no mundo, ocorrendo mais freqüentemente $\mathrm{em}$ áreas tropicais e subtropicais. $\mathrm{O}$ contágio natural deste tumor tem sido atribuído à transmissão por células intactas pelo comportamento social durante o coito e lambedura da genitália infectada. Nào há diferença entre as células de TVT encontrados nos órgãos genitais se comparada com as extra-genitais. Foram utilizados neste estudo 38 cães atendidos no Hospital Veterinário com sinais clínicos e alteraçòes radiográficas compativeis com afecçào nasal crônica. Em todos os càes, antes de proceder o exame de rinoscopia, foram realizados hemograma com contagem plaquetária, exame radiográfico de crânio e tórax. Dos 38 cães submetidos a rinoscopia, houve a ocorrência de 10 càes adultos com TVT nasal, sendo 9 machos e 1 fêmea, a maioria constituída por SRD de porte médio e grande. As alterações mais encontradas em cavidade nasal foram as tumorais com destruição tecidual, sendo observadas fistulas, principalmente em cavidade oral $\mathrm{e}$ isto pode estar associada ao grau de agressividade deste tumor, podendo sugerir uma característica desta afecção nasal. A rinoscopia neste estudo comprovou ser um meio diagnóstico efetivo, não invasivo complementar aos exames fisico e radiográfico, que permite ampla visibilizaçào da cavidade nasal, escolha do local de biópsia servindo como método diagnóstico para este tipo de afecção nasal.

\section{8 - Drenagem de abscessos renais guiados ultra- sonograficamente em cão. Relato de caso}

Kanayama, L. M'; Martín, C. M.2; Coelho B.M.P'; Iwasaki, $M^{4}$
1-M.V. Ms. do Serviço de Diagnóstico por Imagem e Ultra-sonografia da Faculdade de Medicina Veterinária e Zootecnia da Universidade de São Paulo, São Paulo-SP

2- M.V. do Autônoma e Estagiária do Serviço de Diagnóstico por Imagem da Faculdade de Medicina Veterinária e Zootecnia da Universidade de São Paulo, São Paulo-SP

3- M.V. Serviço de Clínica Médica da Faculdade de Medicina Veterinária e Zootecnia da Universidade de São Paulo, São Paulo-SP

4-M.V. Professor Titular do Departamento de Diagnóstico por Imagem da Faculdade de Medicina Veterinária e Zootecnia da Universidade de São Paulo, São Paulo-SP

Os abscessos renais são lesões incomuns, preferencialmente causadas por bactérias coliformes gram negativas como a Escherichia coli. Instalam-se geralmente quando há um processo primário em vias urinárias, tais como obstruçào uretral, cálculos renais, infecçòes no trato urinário de longa duraçào ou recorrentes e refluxo vesico-ureteral. Podem instalar-se raramente devido a outros distúrbios orgânicos. As manifestações clínicas incluem poliúria, polidipsia, debilidade, hipertermia e sensibilidade lombar (renal). O reconhecimento dos sintomas, associado ao exame ultra-sonográfico são essenciais para o diagnóstico precoce da afecçào, melhorando assim o prognóstico do paciente. Atualmente, estudos mostram que a drenagem percutânea guiada por ultra-som tem eficácia em abscessos de tamanho médio, que aliados à terapia antibiótica intensiva, substituem a intervençào cirúrgica tradicional, sem a observaçào de complicaçòes pós-procedimento. $\mathrm{O}$ método utilizado para drenagem é simples, pouco traumático, considerado um procedimento de rotina em pacientes humanos, e extremamente útil quando envolve o trato urinário. O objetivo do trabalho visa demonstrar a eficácia da drenagem dos abscessos renais guiados ultrasonograficamente. Relatamos a drenagem dos abscessos renais em um animal da espécie canina, fêmea, raça Weimaraner, de 3 anos de idade. $\mathrm{O}$ animal apresentava emaciação progressiva, diarréia crônica, poliúria e polidipsia. 